\title{
DUARTE, F. J. C. M., 1995. A Análise Ergonômica do Trabalho e a Determinação de Efetivos: Estudo da Modernização Tecnológica de uma Refinaria de Petróleo no Brasil (Rio de Janeiro) (Mário César Rodriguez Vidal, orientador). Tese de Doutorado, Rio de Janeiro: Coppe, Universidade Federal do Rio de Janeiro. 134p.
}

De acordo com a experiência internacional, a centralização e a integração de salas de controle - modernização tecnológica em curso nas principais refinarias de petróleo no Brasil - têm como um de seus objetivos a redução da mão-de-obra. As equipes de turno passam a ser responsáveis pelo controle de diferentes unidades de produção, o que viabilizaria a diminuição dos efetivos de operação.

As definições em termos de organização do trabalho e suas repercussões sobre a segurança dos sistemas complexos e de alto risco vêm constituindo um importante tema de reflexão no âmbito das modernas tecnologias. Mais do que as falhas dos dispositivos técnicos ou do que os chamados erros humanos, a análise de diversos acidentes, no Brasil e no exterior, mostra que a acumulação de falhas inerentes à organização do trabalho e à concepção dos dispositivos técnicos são a maior ameaça para a segurança das instalações.

A redução de efetivos a que vem sendo submetida a indústria de refino no Brasil relança o antigo debate sobre os critérios pertinentes para a avaliação do número de operadores necessários para assegurar a confiabilidade dessa indústria.

Os critérios disponíveis na literatura são baseados em hipóteses equivocadas a respeito da atividade dos operadores e não se revelam adequados ao dimensionamento da mão-de-obra em atividades de forte componente cognitivo e submetidas a uma variabilidade importante das condições de produção.

A análise ergonômica do trabalho, realizada numa unidade de craqueamento catalítico no Brasil e em unidades petroquímicas francesas que passaram recentemente pela centralização e integração da salas de controle, revela características da operação e funcionamento desses sistemas de produção fundamentais para o dimensionamento da mão-de-obra de operação. Tais características são: o absenteísmo da população; o estado de degradação das instalações; a variabilidade da atividade nas diferentes fases do processo (partidas, paradas, emergências, ...); a concepção do sistema de controle e da automação de procedimentos; a polivalência e repartição de tarefas entre os operadores.

\section{GOMES, R., 1994. O Corpo na Rua e Corpo da Rua: A Prostituição Infantil}

Feminina em Questão (Maria Cecília de Souza Minayo, orientadora). Tese de Doutorado, Rio de Janeiro: Escola Nacional de Saúde Pública, Fundação Oswaldo Cruz. 235 p.

O presente estudo basicamente objetiva analisar a prostituição infantil feminina e o processo saúde-doença, vinculado à sexualidade no meio de meninas do Rio de Janeiro que vivem na rua. Tomando como ponto de partida as representações sociais e baseando-se no recorte de gênero, no caso o feminino, as análises da prostituição infantil feminina, do processo saúde-doença ligado à sexualidade e da violência são articuladas, sem perderem as suas especificidades, no campo da Saúde Pública.

A investigação em questão é de natureza qualitativa, voltada para a análise institucional, utilizando as seguintes técnicas: história de vida, entrevista semi-estruturada, estudo de documentos ligados às organizações e observação participante. Os dados aqui apresentados baseiam-se em fontes primária e secundária. Em termos de fonte primária, destacam-se a observação participante, a entrevista semi-estruturada e, num certo sentido, história de vida. No que diz respeito à fonte secundária, foi levado em consideração um conjunto de três tipos de documentos. O primeiro tipo se relaciona aos documentos específicos sobre as instituições e programas estudados. O segundo integra documentos em que são registrados depoimentos prestados à Comissão Parlamentar de Inquérito sobre Prostituição Infanto-Juvenil. Por último, como terceiro tipo de documento, situam-se obras que relatam pesquisas sobre o assunto ou que analisam a temática da nossa pesquisa em geral. 
Uma das conclusões é que o corpo na rua e o corpo da rua são representações distintas, sendo duas realidades para as meninas que vivem na rua. A primeira expressa a autopercepção que elas têm de si próprias. Já a segunda remete à figura da prostituta que procuram colocar fora de seu universo. No entanto, em ambas as representações se revela a violência sexual. Assim, elas seguem um script comum no cenário social.

Quanto ao processo saúde-doença ligado à sexualidade das meninas que vivem na rua, aspectos da sexualidade ameaçada são ressaltados, tais como: a gestação precoce, o aborto e as doenças sexualmente transmissíveis com comprometimentos da saúde destas meninas. Neste processo, crenças populares podem influenciar estas meninas de uma forma relevante.

Junto à idéia de se promover um amplo projeto de políticas sociais, o atendimento de crianças que vivem na rua demanda ações não só do setor saúde, mas também de outros campos para que esta complexa realidade seja tratada dentro de uma perspectiva interdisciplinar e multiprofissional. Com base nestas considerações, através de uma direta ou indireta participação, a Saúde Pública tem que ter um olhar especial em relação a organizações que atuam com este tipo de clientela.

\section{OLIVEIRA, E. S., 1994. A Questão Alimentar-Nutricional na "Nova República":}

Discurso e Prática (André César Médici \& Maria Helena Machado, orientadores). Tese de Mestrado, Rio de Janeiro: Escola Nacional de Saúde Pública, Fundação Oswaldo Cruz. $134 p$.

Com o discurso dos determinantes da fome e da miséria reaparece na sociedade o debate sobre o papel do Estado na garantia ao direito a uma alimentação digna a toda população. A retomada desta discussão traz à tona o papel do desempenho das políticas de Suplementação Alimentar implementadas pelo governo federal nos últimos anos.

As sucessivas denúncias de desvios, distorções e abusos de ordem político-clientelistas têm trazido o descrédito nessas políticas e a validade de suas intervenções, suscitando questionamentos freqüentes sobre a sua manutenção. Pergunta-se, agora: deve ou não o setor público contribuir para a melhoria dos padrões alimentares, através de distribuição gratuita de alimentos?

Este estudo, portanto, objetiva contribuir para avaliar temas e problemas relacionados ao planejamento e à execução das políticas de suplementação alimentar e verificar se elas realmente estão atendendo às necessidades nutricionais dos grupos vulneráveis.

No período investigado e com base em vasta documentação, o estudo concluiu que os programas e ações estatais destinados à suplementação alimentar dos segmentos mais vulneráveis (gestantes, nutrizes e crianças de baixa renda) não cumpriram os objetivos propostos e nem aliviaram a fome de sua clientela.

RIBEIRO, F. S. N., 1994. Da Identidade do Pesquisado á Identidade da Pesquisa. Os Trabalhadores Brasileiros na Pesquisa Nacional sobre Saúde e Nutrição (Luiz António dos Anjos, orientador). Tese de Mestrado, Rio de Janeiro: Escola Nacional de Saúde Pública, Fundação Oswaldo Cruz. 283 p.

Os homens adultos trabalhadores brasileiros foram estudados num survey nacional, a Pesquisa Nacional sobre Saúde e Nutrição, realizado em 1989.

O objetivo básico foi caracterizar as condições de saúde dos trabalhadores, através das informações de estado nutricional e morbidade referida, entendendo saúde como determinada, em últiima instância, pela forma de inserção dos trabalhadores no processo de produção, neste caso, revelada através da informação de ocupação, reunida em três grandes grupos, segundo a intensidade da atividade física necessária para o seu desempenho: Grupo Leve, Moderado e Intenso.

Outras instâncias consideradas mediadoras desta determinação foram as condições de moradia, a localização geográfica, o nível de instrução, a renda, as horas semanais trabalhadas, a posição e o vínculo de emprego. 
As variáveis tomadas como representativas da situação de saúde foram o estado nutricional, medido através do índice de Massa Corporal (massa corporal.altura ${ }^{-2}$ ) e as três queixas de maior prevalência referidas pelos trabalhadores: cefaléia, nervosismo/depressão e sono/cansaço.

Os resultados apontam para a existência de um duplo perfil de saúde do homem adulto trabalhador brasileiro, caracterizado pela coexistência do sobrepeso com o baixo peso associados, respectivamente, às ocupações com pouca e com intensa atividade física.

O sobrepeso se pronuncia, mais freqüentemente, nos trabalhadores dos Grupos Leves $(36,06 \%)$ e Moderado (33,81\%), que também concentram as melhores condições de moradia, instrução e renda. O baixo peso, entendido como um tipo de desgaste "laboral", é identificado, com maior freqüência, no Grupo Intenso (17,42\%), onde os trabalhadores são submetidos a uma atividade física de alta intensidade. Nestes, também, foram encontradas as piores condições de moradia e instrução e as relações de trabalho mais irregulares.

O sobrepeso em trabalhadores submetidos à utilização alienada das habilidades manuais, configura um Desgaste Paradoxal, na medida em que, tradicionalmente, o Desgaste se associa ao consumo da massa corporal e não ao sobrepeso. O Desgaste Paradoxal, resultante do processo de trabalho, pode estar contribuindo para a atual dimensão do quadro de morbimortalidade por doenças cardiovasculares, no Brasil.

A ocupação assumiu, desta forma, uma importância maior do que tão-somente um fator de identificação do pesquisado. Ao relevar novos parâmetros, reorienta-se a identidade da Pesquisa para uma investigação das condições de saúde dos trabalhadores, a partir de sua ocupação.

\section{RIBEIRO, S. N., 1993. Abandono do Tratamento da Tuberculose: Aspectos do}

Tratamento Malconduzido. Discussão de possíveis fatores como causa do abandono do tratamento específico da tuberculose e a situação bacteriológica após o abandono (Germano Gerhardt Filho, orientador \& Joaquim Valente, co-orientador). Tese de Mestrado, Rio de Janeiro: Instituto de Medicina Social, Universidade do Estado do Rio de Janeiro. $140 \mathrm{p}$.

A não aderência ao tratamento da tuberculose, é considerada, na atualidade, o mais significante problema médico, na área da tuberculose, e as razões não são completamente compreendidas. A União Internacional Contra a Tuberculose (1985) considerou como os principais problemas, relacionados com baixo rendimento dos programas de controle da tuberculose a resistência bacteriana, o custo e a aderência ao tratamento. A não-aderência ao tratamento, passa por diversos níveis, desde o uso irregular das drogas, até a recusa completa do tratamento: "abandono". As responsabilidades deste comportamento, freqüentemente imputadas sobre o doente, na realidade, muitas vezes são dos serviços de saúde. O estudo foi direcionado, especialmente, em relação a um dos aspectos: o abandono do tratamento. O objetivo deste estudo foi determinar variáveis de predição que possam caracterizar o doente que abandona, e com isto facilitar a elaboração de normas para o tratamento e as recomendações de atenção por níveis de cuidados de saúde. O desenho do estudo foi o tipo caso-controle, realizado no ambulatório do HRPS/MS, no ano de 1989. A produção que deu origem aos "casos" (78 doentes com alta por abandono); e aos "controles" (93 doentes que receberam alta por cura e falência) foi a coorte dos doentes matriculados para tratamento da tuberculose. Foram realizadas entrevistas com os doentes e coleta de material para o exame bacteriológico. Foram variáveis associadas aos doentes que abandonaram: (a) ligados ao próprio doente: não ter trabalho fixo, uso diário de bebidas alcoólicas, baixo nível de escolaridade, ausência de estrutura familiar e história passada de tratamento e de abando; (b) ligadas ao serviço de saúde: relação médico-paciente, não-confirmação da tuberculose no diagnóstico, não-seguimento do doente durante o tratamento, hospitalização. Os resultados bacteriológicos, na entrevista, identificaram 50\% dos doentes, que abandonaram, positivos ao exame direto do escarro e a cultura; e taxa de falência de $11,76 \%$, entre os controles. 


\section{SILVA, R. M., 1994. A Teoria Organizacional do Planejamento Estratégico}

Situacional e a Gestão no Setor Saúde. Uma Análise da Experiência da Santa Casa de Misericórdia do Pará (Francisco Javier Uribe Rivera, orientador \& Luiz Carlos de Oliveira Cecílio, co-orientador). Tese de Mestrado, Rio de Janeiro: Escola Nacional de Saúde Pública, Fundação Oswaldo Cruz. 140 p.

Esta pesquisa tem por objetivo analisar as possibilidades de aplicação do modelo gerencial derivado do enfoque de planejamento estratégico-situacional à gestão das organizações de saúde.

Foi desenvolvida, na forma de estudo de caso, sendo realizada uma análise da experiência de mudança organizacional e implantação de um novo modelo gerencial na Fundação Santa Casa de Misericórdia do Pará.

Os resultados observados revelam que a experiência conseguiu imprimir importantes mudanças na dinâmica organizacional, dentre as quais destacamos: descentralização político-administrativa, introdução de uma prática de avaliação do desempenho institucional, gestão colegiada e baseada no processamento técnico-político de problemas e aumento da integração entre os setores administrativos e assistenciais.

A comparação entre o modelo de gestão de Matus e o da Santa Casa mostra importantes semelhanças e algumas diferenças. Dentre as semelhanças destacamos: a modificação simultânea dos sistemas chaves de direção, ênfase na descentralização, na racionalização da agenda do dirigente e na avaliação de resultados. O modelo da Santa Casa se distingue do enfoque matusiano, primeiro, por enfatizar o papel dos atores intra-institucionais, com a criação de espaços coletivos de gestão e de fóruns internos de negociação, visando trabalhar os principais conflitos institucionais. Segundo, por construir um modelo que busca atender às exigências e especificidades destas organizações.

Os resultados da pesquisa revelam que o enfoque estratégico situacional apresenta importantes contribuições para a gestão das organizações de saúde, embora se revele insuficiente para enfrentar alguns problemas relacionados às especificidades destas organizações. As principais contribuições do modelo matusiano são: 1. estratégia de mudança organizacional, baseada na implantação dos sistemas chaves de direção; 2 . ênfase na elevação de responsabilidade institucional mediante a introdução de um sistema de petição e prestação de contas por desempenho, baseado no estabelecimento de compromissos; 3. ênfase na descentralização político-administrativa e flexibilidade organizacional; 4. introdução de uma dinâmica gerencial pautada pelo processamento de problemas em todos os níveis organizacionais; 5. busca por uma coerência entre as regras organizacionais básicas, isto é, as regras de direcionalidade, responsabilidade e governabilidade.

\section{SOTERO, J. A. M. F., 1994. O Dito e o Feito: O Uso dos Recursos Federais na Área de Saúde e os Compromissos da "Nova República" com o Setor (1985/1990) (Solon Magalhães Vianna, orientador \& Sílvia Marta Porto, co-orientadora). Tese de Mestrado: Rio de Janeiro: Escola Nacional de Saúde Pública, Fundação Oswaldo Cruz. 254 p., Bibliografia, Anexos, Tabelas.}

O interesse pelo estudo do orçamento, e seu uso no setor saúde, é motivado pela preocupação com a coerência entre a intenção política e as práticas concretizadas pelas instituições públicas.

O orçamento, um dos mais antigos instrumentos de gestão, particularmente no setor público, tem sofrido várias modificações ao longo do tempo, quer no aspecto conceitual, quer nos aspectos metodológicos e técnicos. No entanto, prevalecem, cada vez mais, as características de instrumento contábil e de controle financeiro. Apesar de fundamentais, estas características minimizam o caráter político que envolve todo o processo de elaboração orçamentária, inserido que está num processo mais amplo, e eminentemente político, que é o do planejamento.

Ao conceber esta dissertação, pretendeu-se resgatar os produtos do processo de elaboração orçamentária - orçamento e balanço - como instrumentos de leitura dos objetivos políticos das duas principais instituições federais do setor saúde - Ministério da Saúde (MS) e Instituto Nacional de 
Assistência Médica da Previdência Social (Inamps) -, no período de governo compreendido entre 15 de março de 1985 e 15 de março de 1990, denominado "Nova República".

Os objetivos políticos, constantes dos procedimentos das autoridades setoriais, bem como documentos de caráter técnico, porém vinculados à operacionalização daqueles objetivos, conformam o que neste estudo foi denominado "conjunto discursivo". Este foi o "pano de fundo", a partir do qual buscou-se entender, na leitura dos orçamentos e balanços do MS e do Inamps, em que sentido foram viabilizados os princípios da eqüidade e da universalidade e a diretriz da descentralização, eixos centrais da reestruturação do setor saúde, assumidos como tal pelo governo no período analisado.

Cabe registrar que não houve a pretensão de reescrever o discurso e, muito menos, emitir julgamento sobre o período de governo. O que se esperava com o estudo era, como já mencionado, ressaltar o orçamento como instrumento de acompanhamento e avaliação do cumprimento dos objetivos políticos. Paralelamente, considerando as importantes mudanças ocorridas no setor saúde no período analisado, e como resultado necessário da leitura dos orçamentos e balanços das duas instituições, esperava-se estar contribuindo para a compreensão da ação institucional para o cumprimento dos princípios e da diretriz estabelecidos.

\section{TELAROLLI JUNIOR, R., 1993. Poder e Saúde: a República, a Febre Amarela e a Formação dos Serviços Sanitários no Estado de São Paulo(Ana Maria Canesqui, orientadora). Tese de Doutorado, Campinas: Faculdade de Ciências Médicas, Universidade Estadual de Campinas. Vol. 1, 246 p.; Vol. 2, 221 p., Bibliografia, Tabelas, Figuras.}

Este trabalho tem por objetivo a investigação das mediações da organização política, em sua vertente estado/municípios, e dos fundamentos tecnológicos das práticas sanitárias, na formação dos serviços de saúde no Estado de São Paulo, entre a Proclamação da República, em 1889, e 1911. A caracterização epidemiológica e demográfica do Estado no período mostrou que o fio condutor da ação sanitária estadual foi o combate às doenças epidêmicas, em especial a febre amarela, que repercutia no funcionamento da máquina administrativa, no cotidiano da população e nas atividades do complexo cafeeiro, desde a imigração subsidiada até a exportação da produção. O padrão tecnológico dos serviços sanitários, de ações de polícia médica executadas na forma de campanhas sanitárias, teve seus fundamentos discutidos, a partir dos debates médicos em torno das teorias sobre as formas de propagação, tratamento e profilaxia da febre amarela, encerrados no início do século XX, com a aceitação da teoria da transmissão da doença pelo vetor.

A formação e o funcionamento dos serviços sanitários no interior paulista apresentaram muitas particularidades em relação aos principais centros urbanos do estado. As relações das lideranças políticas municipais e estaduais, sob o chamado pacto coronelista, suporte regional para a.estrutura de poder oligarquizada da Primeira República, foi fundamental na conformação assumida pelos serviços sanitários no período. Através dos debates no Legislativo estadual, identificou-se o papel de aspectos do ideário republicano, como a defesa do princípio da autonomia municipal e das liberdades individuais, na gestão dos serviços de saúde. A influência desses princípios foi mais marcante no início do período republicano, até 1896, quando predominou um modelo municipalizante dos serviços sanitários. A partir de então, saiu vencedor o pragmatismo das oligarquias cafeeiras, em defesa de seus interesses políticos e econômicos imediatos, resultando na estadualização das ações sanitárias. 